\title{
Diagnostic Measurement for the Effective Performance of Motor Vehicles
}

\author{
István Lakatos \\ Széchenyi István University \\ Department of Road and Rail Vehicle \\ Egyetem tér 1, H-9026 Győr, Hungary \\ lakatos@sze.hu
}

Abstract: Diagnostics means instrumental measurement without dismantling. So measuring the engines on rolling roads is not incorporated in this concept, as this measurement is accomplished on engines taken out from vehicles. During service, it is often necessary to measure the performance of the engines, or to judge the performance projection of some corrections. The new method discussed in this article provides a solution to this problem.

Keywords: drive train; wheel performance; effective performance; free acceleration

\section{Introduction}

The measurement of the effective performance of motor vehicles takes place with the aid of bench tests that suggest a dismantled engine. The results of this in case of engines are the usually available so called external or total load characteristics.

In the case of operating vehicles, the possibility to take such measurements is quite rare. During diagnostics and repair work it is necessary more and more frequently to measure the effective moment and performance of the engines.

Some rolling roads possess these kind of skills; however even their prices exceed the budget of the services.

Henceforth, I introduce the theoretical background of a new measurement method with accessible instruments [6]. 


\section{Measuring Engine Performance on Free Rollers}

\subsection{The Theoretical Background of the New Measurement Method}

The principle of the measurement method is to accelerate and decelerate the unloaded drive train of the studied vehicle on free rollers (there is no need for a rolling road). Since we want to measure external characteristics, the measurement must be performed under total load conditions [1], [2].

Let us write the energy equation for the system displayed in Figure 1; according to this equation the temporal change of the introduced work in the system $\left(\mathrm{P}_{\mathrm{e}}-\right.$ effective engine performance) equals to the temporal changes of the kinetic energy $\left(E_{k}\right)$, the potential energy $\left(E_{p}\right)$ and the diverted heat $(Q)$ :

$$
P_{e}=\frac{\mathrm{dE}_{\mathrm{k}}}{\mathrm{dt}}+\frac{\mathrm{dE}_{\mathrm{p}}}{\mathrm{dt}}+\frac{\mathrm{dQ}}{\mathrm{dt}}
$$

As the potential energy does not change during the measurement:

$$
\mathrm{P}_{\mathrm{e}}=\frac{\mathrm{dEk}}{\mathrm{dt}}+\frac{\mathrm{dQ}}{\mathrm{dt}}
$$

The kinetic energy change of the system is displayed in the acceleration of the wheel and the rollers, so this element equals to the wheel performance $\left(\mathrm{P}_{\mathrm{k}}\right)$. Though the diverted heat equals to the running loss performance $\left(\mathrm{P}_{\mathrm{v}}\right)$ :

$$
\mathrm{P}_{\mathrm{e}}=\mathrm{P}_{\mathrm{k}}+\mathrm{P}_{\mathrm{v}}
$$

The basic dynamic equation of rotation can be prescribed both for acceleration and deceleration phases:

$$
\mathrm{P}=\mathrm{M} \cdot \omega=\left(\theta_{\text {red }} \cdot \varepsilon\right) \cdot \omega=\theta_{\text {red }} \cdot \frac{\mathrm{d}^{2} \varphi}{\mathrm{dt}^{2}} \cdot \frac{\mathrm{d} \varphi}{\mathrm{dt}}
$$

where:

- $\omega$ the angular velocity of the roller of the rolling road

- $\Theta_{\text {red }}$ moment of inertia of the drive train of the vehicle reduced to the shaft of the roller of the rolling road

- $\varphi$ angular displacement of the roller

- $\varepsilon \quad$ angular acceleration of the rollers

- $\mathrm{t}$ time 
The basic equation of the acceleration phase:

$$
\begin{aligned}
& \mathrm{P}_{\text {veszt }}=\mathrm{P}_{\mathrm{v}, \mathrm{f}(\mathrm{M})}^{\prime \prime}+\mathrm{P}_{\mathrm{v}, \mathrm{f}(\omega)}+\mathrm{P}_{\mathrm{vpad}, \mathrm{f}(\mathrm{vg})} \\
& \mathrm{P}_{\text {kerék }}=\omega_{\mathrm{g}} \cdot \varepsilon_{\mathrm{g}}^{+} \cdot\left[\theta_{\text {mot,red }}+\theta_{\text {jármüŕred }}+\theta_{\mathrm{pad}}\right]
\end{aligned}
$$

where:

- $\mathrm{f}(\mathrm{M})$ the $\mathrm{f}(\mathrm{M})$ index elements are the losses depending on the tractive force

- $f(\omega)$ the $f(\omega)$ index elements are the losses depending on the velocity

- $\mathrm{g}$-index roller

- $\Theta_{\text {mot, red }} \quad$ value of the moment of inertia of the engine reduced to the shaft of the roller

- $\Theta_{\text {jármü, red }} \quad$ value of the moment of inertia of the vehicle reduced to the shaft of the roller

- $\Theta_{\text {pad, red }} \quad$ value of the moment of inertia of the rolling road reduced to the shaft of the roller

- ${ }^{+}$-index acceleration

- -index deceleration

The basic equation of the deceleration phase:

$$
\begin{aligned}
& \mathrm{P}_{\text {veszt }}=\mathrm{P}_{\mathrm{v}, \mathrm{f}(\mathrm{M})}^{\prime}+\mathrm{P}_{\mathrm{v}, \mathrm{f}(\omega)}+\mathrm{P}_{\mathrm{vpad}, \mathrm{f}(\mathrm{vg})} \\
& \mathrm{P}_{\text {fékezö }}=\omega_{\mathrm{g}} \cdot \varepsilon_{\mathrm{g}}^{-} \cdot\left[\theta_{\text {jármüŕed }}+\theta_{\mathrm{pad}}\right]
\end{aligned}
$$

In the aforementioned equations the alternations of $P_{v, f(M)}$ value marked with one or two commas refer to a different loss proportion in the acceleration and the deceleration phases, as in the latter phase the engine is separated from the system.

The phases of the measurement are the following:

1 ACCELERATION PHASE: The drive train of the vehicle on the bench and the rollers of the rolling road are accelerated, in the studied gear accelerated up to the rated engine speed with full load (on full blast).

2 DECELERATION PHASE: By releasing the clutch, leaving the gear at the given position, we let the car decelerate until it stops.

During the measurement, as there is no external load, the engine has to accelerate the moments of inertia indicated in Figure 1. During the deceleration we separated the moment of inertia of the engine, so with this exemption the rest of the moments of inertia decelerate the system. 


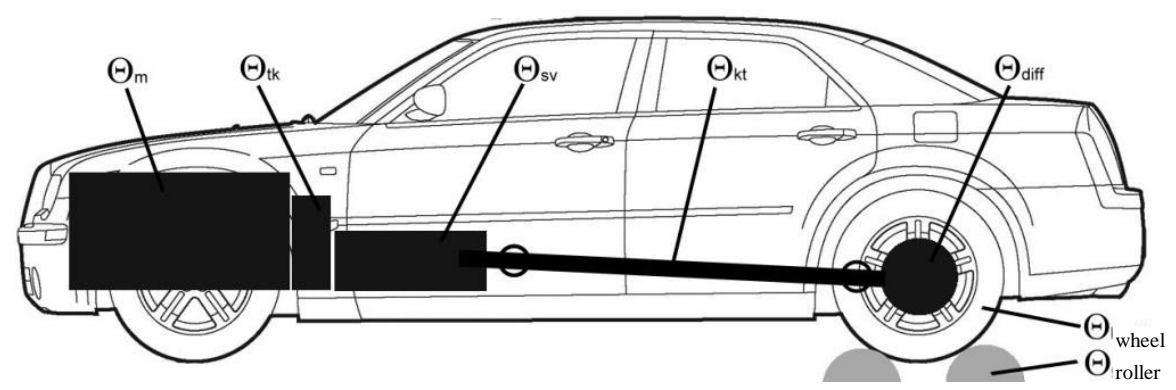

Figure 1

Vehicle drive train on free rollers

During the measurement only one transmitter is needed; we need to measure the revolution number $(n)$ of the shafts of the rollers (roller radius: $r_{g}$ ). From this we can formulate the following data:

- angular velocity:

$\omega=\frac{d \varphi}{d t}=2 \cdot \pi \cdot n$,

- angular acceleration:

$\varepsilon=\frac{d \omega}{d t}$

- $\quad$ vehicle speed (the circumferential velocity of the wheel, and the roller)

$$
v=r_{g} \cdot \omega
$$

According to the aforementioned measurements the diagram displayed in Figure 2 can be recorded.

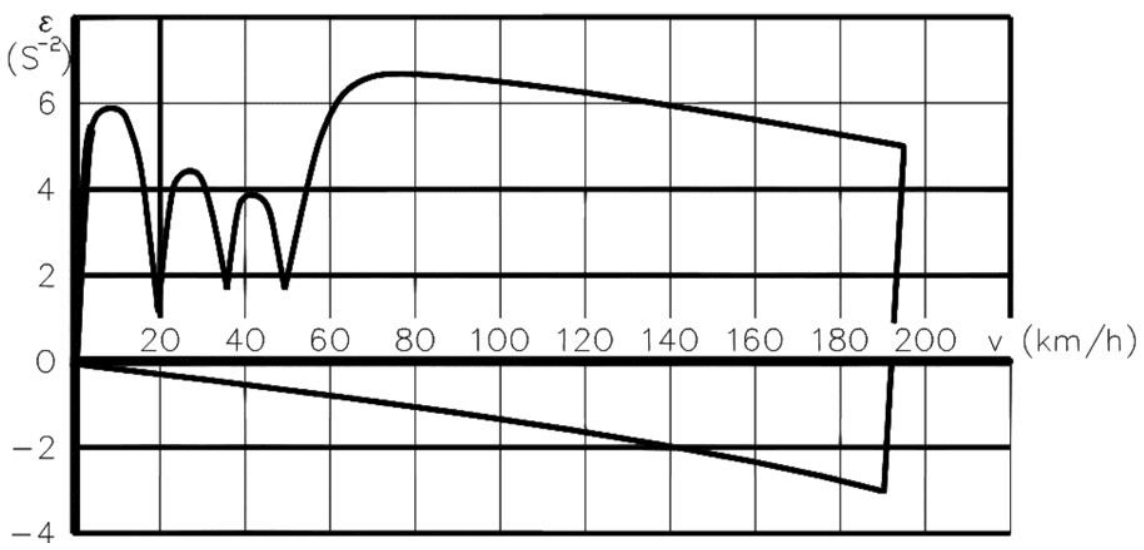

Figure 2

Characteristic curve recorded during the measurement

The following fundamental mechanic equations should be taken into further consideration:

$M=\theta \cdot \varepsilon$ 
and

$P=M \cdot \omega=\theta \cdot(\varepsilon \cdot \omega)$

In accordance with the aforementioned equations we mean by $\Theta$ the reduced moment of inertia on the shaft of the roller $\left(\Theta_{\text {red }}\right)$, as we also measure the revolution number on the shaft of the roller.

According to the aforementioned ideas we can state:

$M(v) \sim \varepsilon(v)$

$P(v) \sim(\varepsilon \cdot \omega)(\mathrm{v})$

Namely, the $\varepsilon$ function is in accordance with the full load torque curve as regards the features of vehicle speed (or even revolution number), while ( $\omega . \varepsilon)$ function is parallel to the performance curve.

\subsection{Practical Considerations of the Measurement}

The performance rated functions can be seen in Figure 3. It must be interpreted before moving on:

1 ACCELERATION PHASE: the roller is accelerated by the wheel of the vehicle, thus the function taken with the measurement $(\omega . \varepsilon)$ is proportional with the wheel performance.

2 DECELERATION PHASE: The roller and the drive train are decelerated by the loss of the units after the engine, namely the loss performance.

Namely:

$P_{\text {wheel }}=P_{\text {eff }}-P_{\text {loss }}$

In reverse:

$P_{\text {eff }}=P_{\text {wheel }}+P_{\text {loss }}$

Where:

- $\mathrm{P}_{\text {eff }} \quad-$ the effective performance of the engine

- $\mathrm{P}_{\text {loss }}-$ the loss of the drive train

- $\mathrm{P}_{\text {wheel }} \quad$ the performance deduced on the wheel

The practical realization of the latter function can be seen in Figure 3, where the summary of the proportionate functions about the performance of the wheels and the loss of the drive train are indicated. The resultant function is a proportionate curve with the (effective) performance of the engine. 


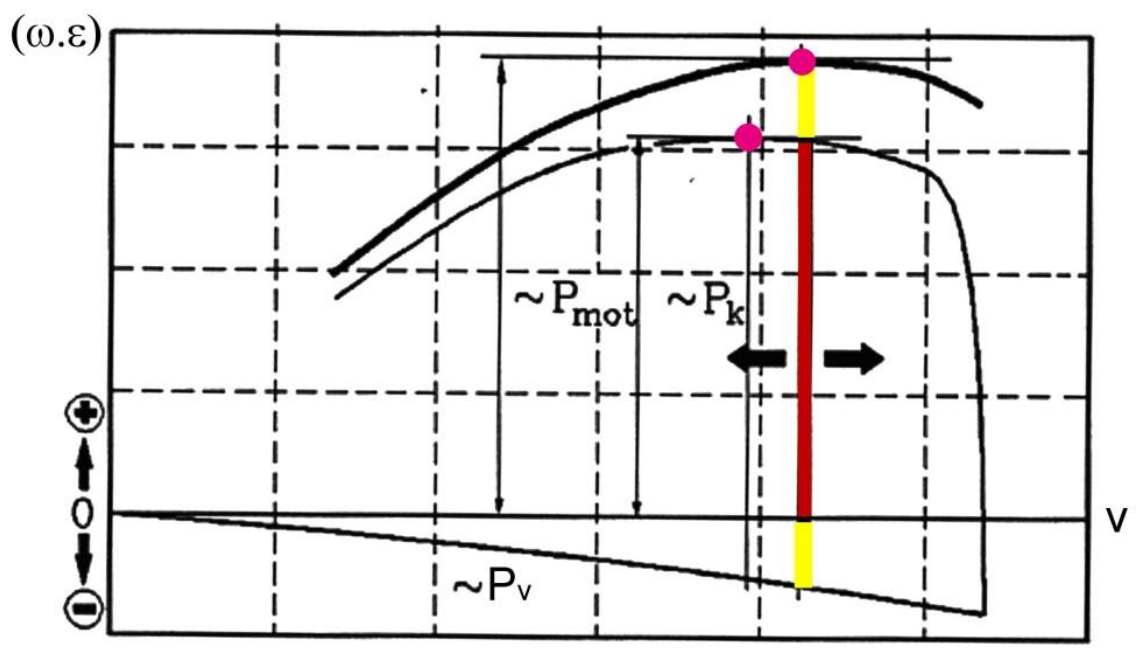

Figure 3

Performance proportionate characteristic curve recorded during the measurement

\section{Evaluation of the Measurement Results}

The main condition for evaluating the results of the measurement is to know the moment of inertia indicated in the Figure 1. Although these values are not available, their shortage can be eliminated with an adequate measurement procedure.

\subsection{Validating the External Characteristic Curve of the Engine by Roller Bench Test}

If we possess not only rollers but our measuring rollers are the rollers of a vehicle bench pad, we have to find the velocity value $\left(\mathrm{v}^{*}\right)$ that belongs to the local maximum of the acceleration phase indicated in Figure 3 [3], [4].

As a next step we choose the load characteristics of constant velocity on the roller bench, we set the $\mathrm{v}^{*}$ velocity, and then we measure the wheel performance with full load (Figure 4).

With these steps the values appear in $\mathrm{kW}$ even on the vertical axis of Figure 3, i.e. the effective performance curve of the engine is available. 


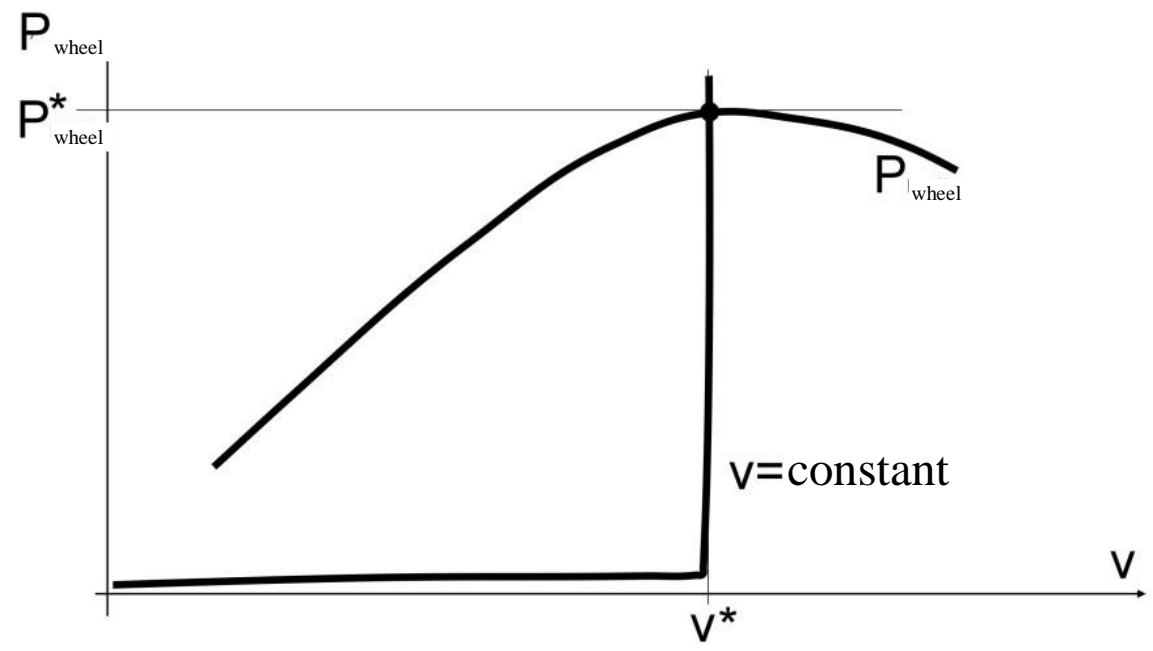

Figure 3

Performance proportionate characteristic curve recorded during the measurement

The flaw in this method is that the scales of the diagram phases of the acceleration and deceleration are not equal, as in one case we should take into consideration the (unknown) moment of inertia of the engine, while in the other case it is not needed. This fact can be considered only with a correction factor defined empirically (generally 10\%).

\subsection{Validating the External Characteristic Curve of the Engine without Roller Bench Test (New Measurement Method)}

The main point of the measurement method which I elaborated is the following:

If we do not possess a rolling road, just a roller bed, we need to conduct two free acceleration measurements.

\section{$\underline{1^{\text {st }} \text { Measurement }}$}

Actually, this is equal with the previously mentioned measurement method. Equations:

$P_{k, 1}=\left(\theta_{\text {engine,red }}+\theta_{\text {drive train,red }}\right) \cdot \varepsilon_{1} \cdot \omega_{1}$

$P_{v, 1}=\theta_{\text {drive train,red }} \cdot \varepsilon_{1} \cdot \omega_{1}$

$\underline{2^{\text {nd }} \text { Measurement }}$

In this case we tie an additional flywheel to the shaft of the rollers, which enhances the total reduced moment of inertia calculated for the shaft of the roller. 


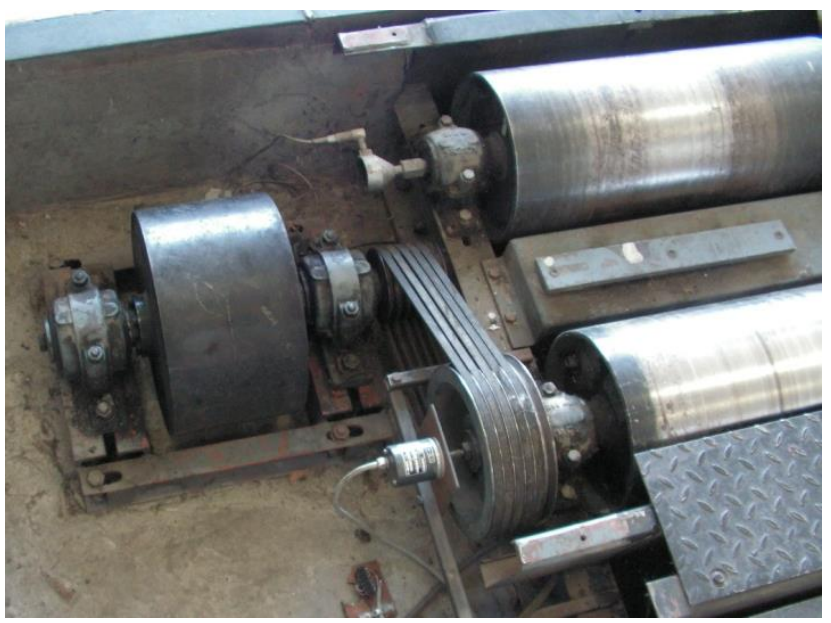

Figure 4

Roller bench with the rotating mass

$P_{k, 2}=\left(\theta_{\text {engine,red }}+\theta_{\text {drive train,red }}+\theta_{\text {flywheel,red }}\right) \cdot \varepsilon_{2} \cdot \omega_{2}$

$P_{v, 2}=\left(\theta_{\text {drive train,red }}+\theta_{\text {flywheel,red }}\right) \cdot \varepsilon_{2} \cdot \omega_{2}$

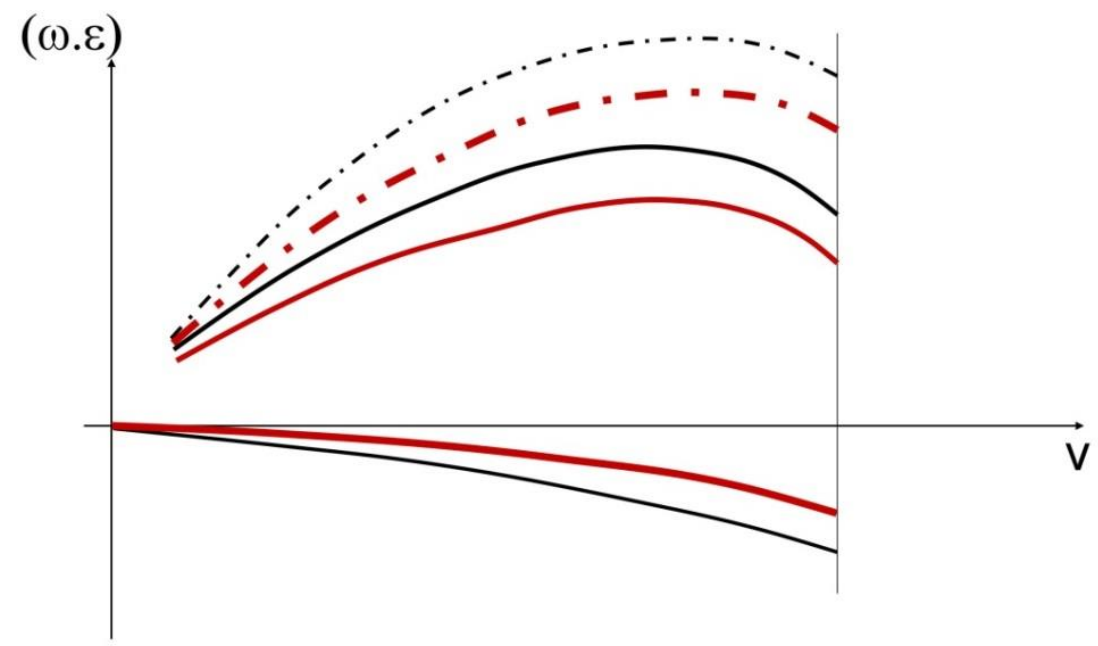

Figure 5

Diagrams of two subsequent measures

Although in both of these cases the inertia and naturally the acceleration and deceleration of the system are diverse, by calculating the performance the performances through the wheel and the performance loss must correspond with each other, since the engine that accelerates the system and the drive train that has losses are unaltered. 
Consequently, in the case of the $1^{\text {st }}$ and $2^{\text {nd }}$ measurements, the equations of the wheel performance and the drive train loss can be equated in couples:

$$
\begin{aligned}
& \left(\theta_{\text {engine,red }}+\theta_{\text {drive train,red }}\right) \cdot \varepsilon_{1} \cdot \omega_{1} \\
& \quad=\left(\theta_{\text {drive train,red }}+\theta_{\text {flywheel,red }}\right) \cdot \varepsilon_{2} \cdot \omega_{2}
\end{aligned}
$$

$\theta_{\text {drive train,red }} \cdot \varepsilon_{1} \cdot \omega_{1}=\left(\theta_{\text {drive train,red }}+\theta_{\text {flywheel,red }}\right) \cdot \varepsilon_{2} \cdot \omega_{2}$

Thus the following is derived from the $2^{\text {nd }}$ equation:

$\theta_{\text {drive train,red }}=\frac{\left(\varepsilon_{1} \cdot \omega_{1}-\varepsilon_{2} \cdot \omega_{2}\right)}{\theta_{\text {flywheel, } r e d} \cdot \varepsilon_{2} \cdot \omega_{2}}$

In the above equation the numerator is measured, and the denominator is a datum known from the construction. On the basis of this, with the help of the 1 st equation, even the moment of inertia of the engine can be determined.

All of this process is naturally controlled and calculated with the aid of adequately elaborated measuring software. Consequently, the end result will be an external characteristic curve of torque and performance defined by exact values.

\section{Summary}

There are several advantages to elaborating a new measuring system [5]:

1 There is no need for a rolling road, and therefore simpler and cheaper measuring devices can be developed.

2 The measurement is more precise, since it defines everything on the basis of measuring excluding empirical correction factor.

The described new method provides an available opportunity for professional services, as it is able to define the diagnostic performance of the engine with required exactness.

It is a very important achievement that with the help of diagnostic tools (without the removal of the engine) we can get an accurate result of the effective performance of the engine, as it significantly differs from the performance result of the wheels that can be measured on the rolling road (Figure 6). 


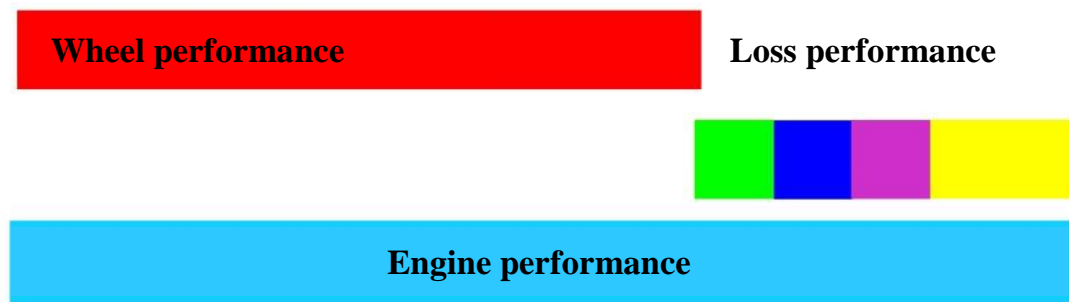

Gearbox

Gearing

\section{Bearing friction}

\section{Resistance to rolling}

Figure 6

Wheel performance- drive train losses - effective performance of the engine

The value of these losses (Figures 7 and 8) cannot be defined with measuring or can only be defined with difficulty.

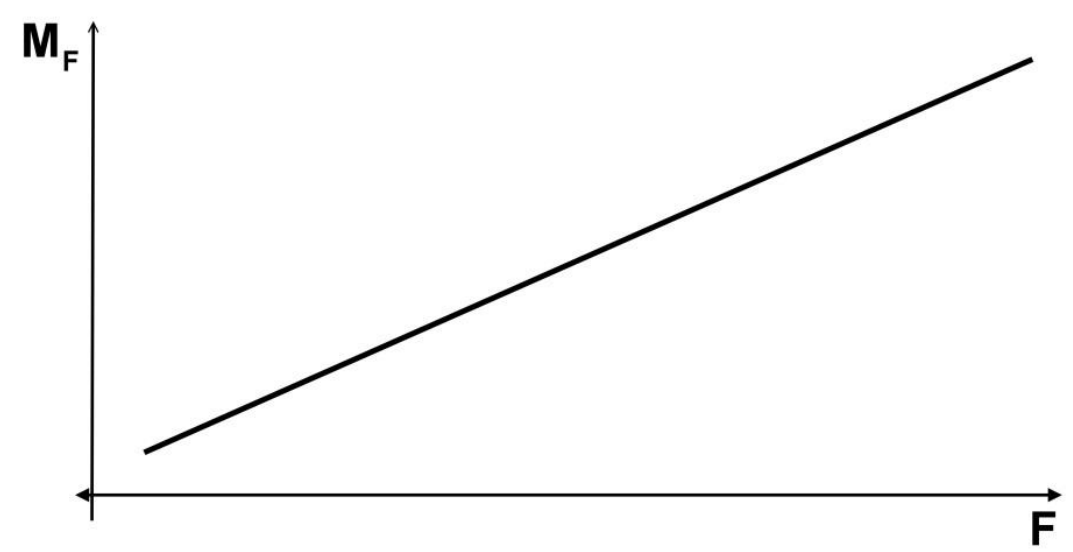

Figure 7

Loss depending on tractive force (Gear wheel friction, slip)

Ultimately the most significant result of the new procedure is that it enables us to measure the effective performance of the engine, for which we usually possess reference data, with adequate accuracy in a testing bench. 


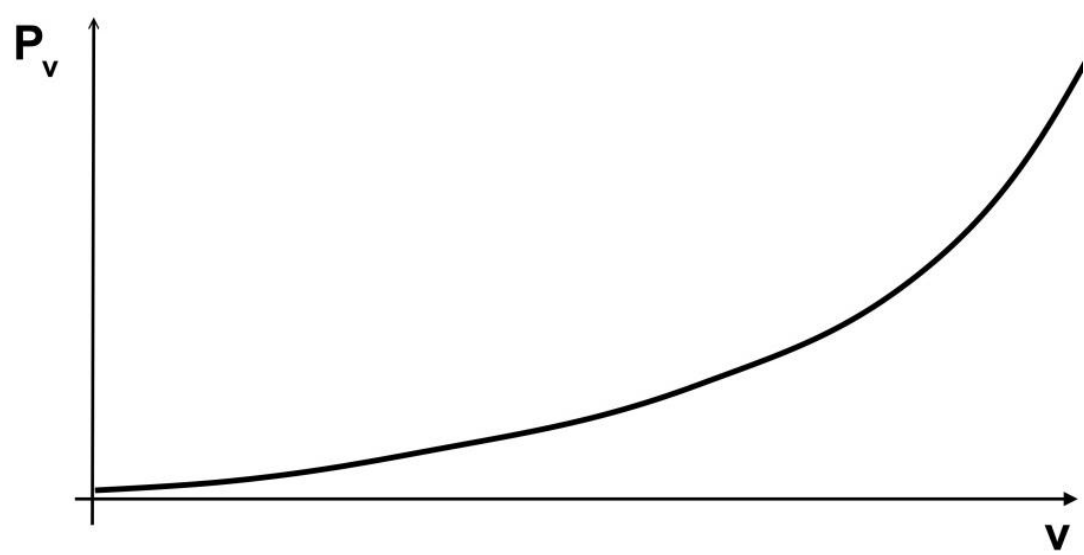

Figure 8

Loss depending on velocity (oil mixing, ventilation, tyre kneading work)

\section{References}

[1] Dr. Lakatos István: Analyse der Zusammenhängen zwischen indizierten Motorkennwertwen und Rollprüfstanduntersuchungsergebnissen, JÁRMÜVEK 49:(6) pp. 31-34. (2002)

[2] Dr. Lakatos I.: Comparative Measures on Rolling Road Dynamometers, XXV microCAD International Scientific Conference, 31 March - 1 April 2011, Miskolc, Hungary, pp. 57-64

[3] Dr. Lakatos I.: Gasoline Engine Diagnostic on Chassis Dynamometers, XIX microCAD International Scientific Conference, 18-20 March, 2010, Miskolc, Hungary, pp. 27-32

[4] Dr. Lakatos I.: Instacioner Engine Performance Measure on Rolling Road Dynamometers, XIX microCAD International Scientific Conference, 18-20 March, 2010, Miskolc, Hungary, pp. 33-38

[5] Dr. Lakatos I.: Measuring Engine Performance with Diagnostic Tools, Innovation and Sustainable Surface Transportation Conference, 3-5 September 2010, Budapest, Conference material on CD

[6] Dr. Lakatos I.: Motorteljesítmény mérés diagnosztikai eszközökkel In: Péter Tamás (ed.) Innováció és fenntartható felszíni közlekedés konferencia: IFFK 2010, Budapest, Hungary, Sept. 2-4, 2010, Budapest: BMF; Magyar Mérnökakadémia, 2010 (ISBN 978-963-88875-1-1) CD proceedings 